\title{
Idiopathic Renal Papillary Necrosis
}

National Cancer Institute

\section{Source}

National Cancer Institute. Idiopathic Renal Papillary Necrosis. NCI Thesaurus. Code C123195.

Necrosis of the renal papillae, for which no underlying cause has been identified. 